\title{
A Food Photograph Series for Identifying Portion Sizes of Culturally Specific Dishes in Rural Areas with High Incidence of Oesophageal Cancer
}

\author{
Martani Lombard ${ }^{1, *}$, Nelia Steyn ${ }^{2}$, Hester-Mari Burger ${ }^{3,4}$, Karen Charlton ${ }^{5}$ and \\ Marjanne Senekal ${ }^{6}$
}

1 Division of Human Nutrition, Stellenbosch University, Cape Town 8000, South Africa

2 Population Health, Health Systems and Innovation, Human Sciences Research Council, Cape Town 8000, South Africa; E-Mail: npsteyn@hsrc.ac.za

3 Department of Biochemistry, Stellenbosch University, Cape Town 8000, South Africa;

E-Mail: hester.burger@mrc.ac.za

4 PROMEC Unit, South African Medical Research Council, Cape Town 8000, South Africa

5 School of Health Sciences, Faculty of Health \& Behavioural Sciences, University of Wollongong, NSW 2500, Australia; E-Mail: karenc@uow.edu.au

6 Division of Human Nutrition, University of Cape Town, Cape Town 8000, South Africa;

E-Mail: marjanne.senekal@uct.ac.za

* Author to whom correspondence should be addressed; E-Mail: martani@sun.ac.za;

Tel.:+27-21-933-1408; Fax: +27-21-933-2991.

Received: 17 June 2013; in revised form: 30 July 2013 / Accepted: 30 July 2013 /

Published: 6 August 2013

\begin{abstract}
Rural areas of the Eastern Cape (EC) Province, South Africa have a high incidence of squamous cell oesophageal cancer (OC) and exposure to mycotoxin fumonisin has been associated with increased OC risk. However, to assess exposure to fumonisin in Xhosas - having maize as a staple food - it is necessary to determine the amount of maize consumed per day. A maize-specific food frequency questionnaire (M-FFQ) has recently been developed. This study developed a food photograph (FP) series to improve portion size estimation of maize dishes. Two sets of photographs were developed to be used alongside the validated M-FFQ. The photographs were designed to assist quantification of intakes (portion size photographs) and to facilitate estimation of maize amounts in various combined dishes (ratio photographs) using data from $24 \mathrm{~h}$ recalls $(n=159)$, dishing-up sessions $(n=35)$, focus group discussions (FGD) $(n=56)$ and published literature. Five villages in two rural isiXhosa-speaking areas of the EC Province, known to have a high
\end{abstract}


incidence of OC, were randomly selected. Women between the ages of 18-55 years were recruited by snowball sampling and invited to participate. The FP series comprised three portion size photographs (S, M, L) of 21 maize dishes and three ratio photographs of nine combined maize-based dishes. A culturally specific FP series was designed to improve portion size estimation when reporting dietary intake using a newly developed M-FFQ.

Keywords: fumonisin; mycotoxins; oesophageal cancer; food photograph series; maize; dietary intake

\section{Introduction}

A relatively small geographic area in rural areas of the Eastern Cape (EC) Province of South Africa has a high incidence of squamous cell oesophageal cancer (OC) [1]. The aetiology of OC is still unclear; however various risk factors have been associated with the disease including alcohol consumption [2], tobacco use [2], and exposure to the carcinogenic mycotoxin fumonisin [3]. Of particular interest in the South African context is the high exposure to mycotoxins (fumonisin moniliforme) in these areas [3-5]. Past research has shown that fumonisin grow on maize that is stored in suboptimal damp conditions and are found in higher concentrations in home-grown compared to commercially sold maize [5]. Maize is the primary staple food of the black population of South Africa and is consumed in large amounts on a daily basis in the geographical area of interest $[3,4]$. Fumonisin contamination of this food source is a major health concern and to date no quantitative assessment of exposure has been conducted [6]. Recently, a culturally specific maize-specific food frequency questionnaire (M-FFQ) was developed [7] to determine fumonisin exposure from maize consumption in rural-dwelling residents of the EC Province.

Accurate assessment of fumonisin exposure in isiXhosa-speaking subsistent farmers whose staple food is maize requires determination of maize consumed in various dishes throughout the day. Maize is typically consumed with vegetables, and the ratio of maize to vegetables varies according to availability of vegetables [8,9]. This variation to commonly consumed dishes makes it difficult to estimate the actual amount of maize consumed and requires determination of the ratio of maize to vegetable.

Minimizing measurement error is important when determining diet-disease association. Classification of people based on their food and therefore nutrient intake is determined by the accuracy of the dietary assessment tool used. Therefore, using dietary assessment tools with known measurement errors, the attenuating effects of misclassification can be assessed and interpreted [10].

A key error occurring in the measurement of food intake occurs during portion size assessment. The use of scales is often problematic or not appropriate and then the assessment of food intake depends on the participant's ability to remember and describe their usual portion size [10]. Various aids have been developed to improve participants' description of their usual portion size (such as portion size models, food models, photographs and schematic diagrams).

In a study conducted by Nelson et al., (1996) it was concluded that photographs that depicts a range of portion sizes can be used to improve portion size estimation and that the use of such photographs 
can further reduce the misclassification of participants. It was however reported that factors such as participant age, gender and body mass index can influence portion size estimation [10].

Owing to culturally specific dietary habits [11], existing food portion size photographs that represent Western, mainly urban-type meals could not be used in this population. The aim of the present study was to develop a culturally specific series of food photographs (FPs) to be used as an aid when conducting dietary interviews in order to improve portion size estimation of maize-based meals and beverages, such as traditional maize-beer.

Figure 1. Process followed for the development of the portion size and ratio photographs.

\section{DEVELOPMENT OF STANDARD PORTION SIZES AND RATIO PHOTOGRAPHS}

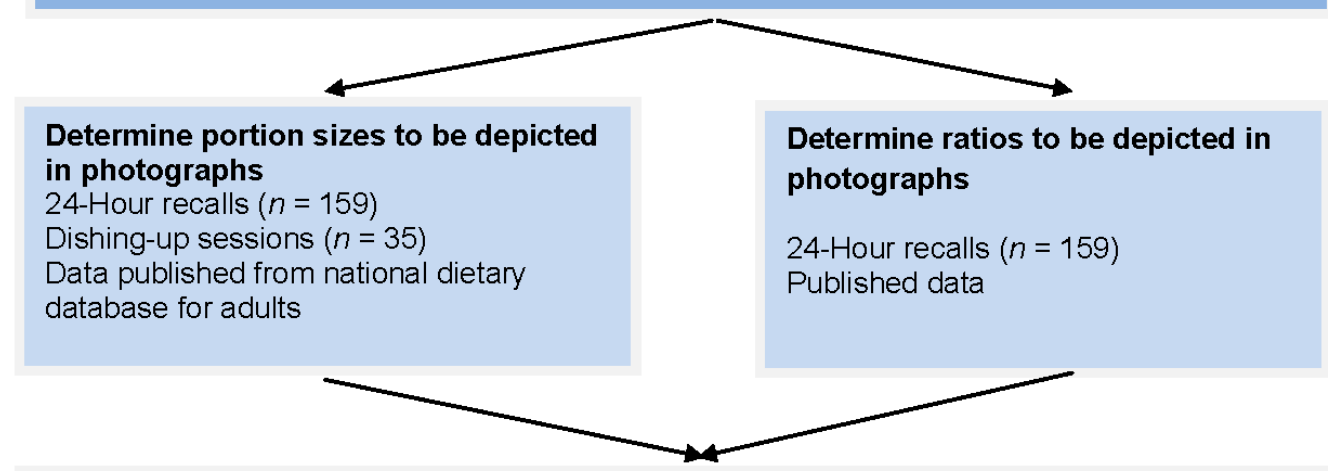

Draft 1: Preparation and development of photographs

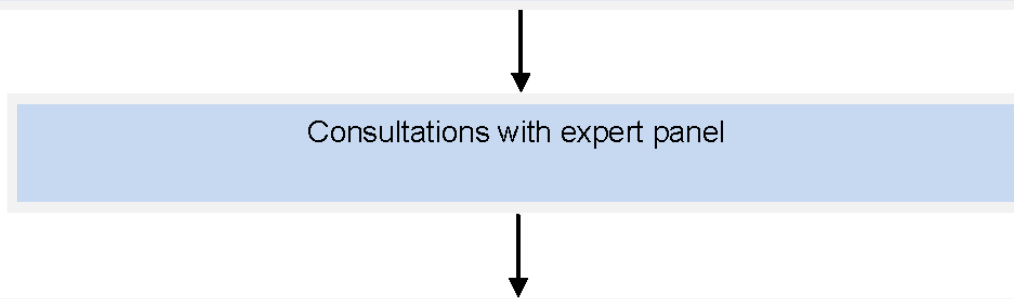

Draft 2: Preparation and development of photographs

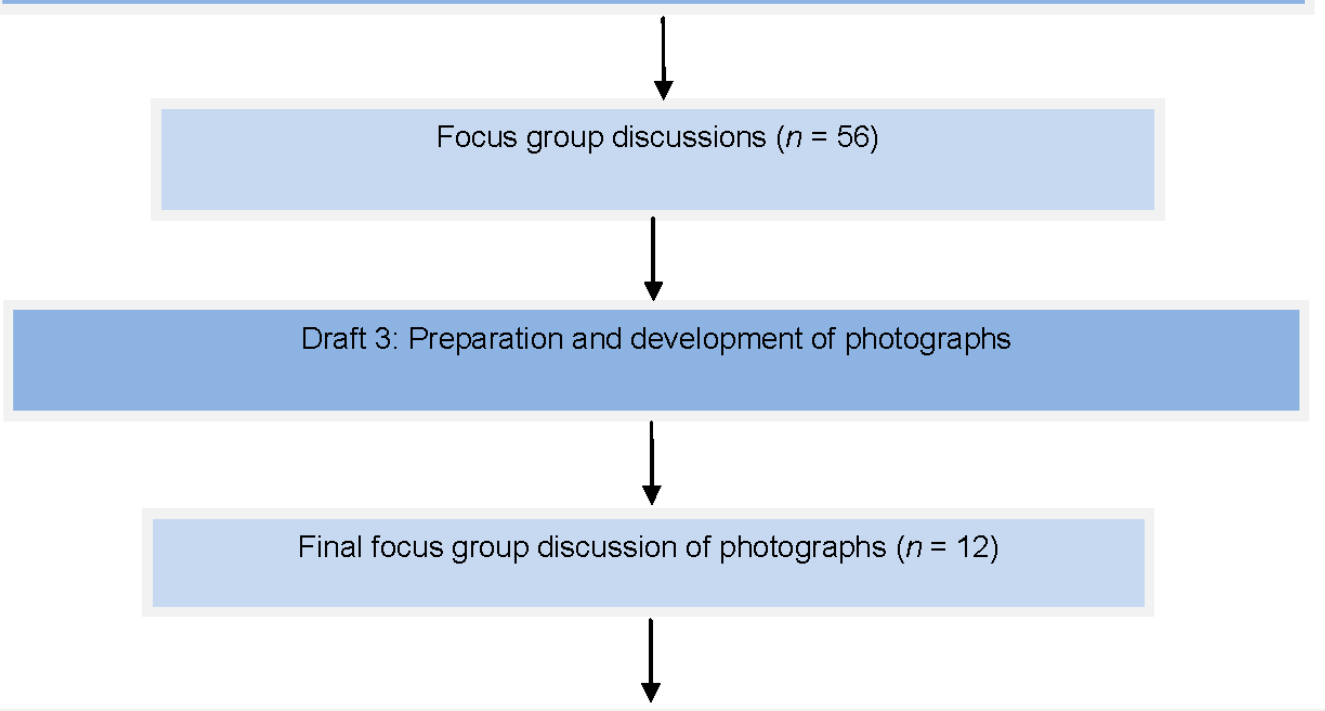




\section{Materials and Methods}

\subsection{Overview}

As shown in Figure 1, the initial FPs on maize, maize-vegetable combined dishes, and maize beverages $(n=21)$ were developed based on data obtained from (i) a survey using $24 \mathrm{~h}$ recalls from EC Province; (ii) women from the study area dishing up their "usual" serving portions and (iii) data on portion sizes obtained from a national database. In addition to the determination of portion size it was also necessary to determine the ratio of maize to vegetables in "combined dishes". This was done by reviewing published data and data from a study using $24 \mathrm{~h}$ recalls from the EC Province.

After the initial FPs were finalised (Draft 1) they were shown to an expert group for comment; the FPs were subsequently revised (Draft 2). This was followed by focus group discussions (FGD) with participants recruited from the target study population, who made further recommendations, which resulted in Draft 3. A last FGD resulted in the final set of FPs. Each step is discussed in detail below.

\subsection{Determination of Portion Sizes}

\subsubsection{Use of 24-h Recalls}

Standard portion sizes of maize items, dishes and beverages appearing on the M-FFQ were determined using $24 \mathrm{~h}$ recall data $(n=159)$ collected in the same areas [7]. Participants provided information on the maize based food items and dishes consumed the previous day, as well as snacks and beverages to provide information on the dietary habits of the people living in these areas. The objective of the reviews was to identify commonly consumed food items and dishes as well as cooking and food preparation methods.

\subsubsection{Dishing up Sessions}

Dishing-up (serving) sessions were undertaken in the selected areas to determine the standard portion sizes of these M-FFQ dishes: stiff pap (maize meal porridge with a stiff, thick consistency), soft porridge (maize meal porridge having a thin consistency), samp (whole maize kernels) and beans, spinach/imifino (a wild leafy vegetable similar to spinach) combined with pap, pumpkin combined with pap, and soup/isophi (watery soup consisting of whole maize kernels and dried sugar beans). Two rural areas of the EC Province were selected because of the high incidence of OC [1]. Because of poor infrastructure; villages from each area were randomly selected. Female volunteers were recruited with snowball sampling. Six women were identified and prepared the six most commonly consumed maize dishes using ingredients provided by the research team.

Thirty five female volunteers (18-55 years) were recruited and asked to dish up a "usual" portion that they would serve an adult male and female living in the household. The served portions were individually weighed on the plate. The weight of the plate subtracted to provide a portion size. Participants were informed that they would not be eating the food so that neither their current state of hunger, nor the fact that the food was free would influence the dishing up process [12].

The mean weight for each dish was determined and the inter quartile (IQ) range $(25 \%, 50 \%$ and $75 \%$ percentiles) were used to determine $\mathrm{S}, \mathrm{M}$, and $\mathrm{L}$ portion sizes of each dish. 


\subsubsection{Data from a National Database}

Portion sizes for dishes not included in the dishing-up sessions were determined from a national dietary database on dietary intake compiled from studies that were conducted among different population groups in South Africa from 1983 to 2000 [13]. Two studies conducted in similar rural communities formed part of this data base.

\subsection{Determination of Ratios Depicted in Food Photograph Series}

Standard ratios of maize to vegetables in nine combined dishes (maize meal + imifino; maize meal + spinach; maize meal + pumpkin; maize meals + dried beans; maize meal + dried beans; samp + beans; isophi; mealie rice + spinach; mealie rice + pumpkin) were determined using previously unpublished $24 \mathrm{~h}$ recall data from our group $(n=159)$ [7], as well as review of previously published data $[8,9]$.

\subsection{Preparation and Development of Initial Photographs}

Maize dishes depicted on the initial FPs were prepared by a woman born and raised in the area. Raw ingredients were weighed and cooking methods and preparation steps recorded. An initial FP series (Draft 1) was developed. Photographs were taken at an angle of $42^{\circ}$ above the horizon, which is the average angle of viewing when a person is seated at a table) [14]. Different colour backgrounds, reference scales, types of and colour plates were considered in the process (Table 1).

Table 1. Different factors considered in developing the photographs.

\begin{tabular}{|c|c|c|}
\hline Factors considered & Photograph options & Influence of photographs \\
\hline \multirow[t]{4}{*}{ Colour of the plate } & White & $\begin{array}{l}\text { Maize dishes are white and therefore there was little } \\
\text { contrast between the food and the plate. }\end{array}$ \\
\hline & Yellow or cream & Influenced the colour of dishes containing pumpkin. \\
\hline & Green & Influenced the colour of dishes containing spinach. \\
\hline & Blue & Influenced some of the photographs containing spinach. \\
\hline \multirow[t]{2}{*}{ Type of plate used } & Bowl & $\begin{array}{l}\text { Determining the depth of the dish was difficult when it is } \\
\text { presented in a bowl. }\end{array}$ \\
\hline & Plate & Determining depth on a plate was easier than that of a bowl. \\
\hline $\begin{array}{l}\text { Background of the } \\
\text { photograph }\end{array}$ & Dark (navy or black) & $\begin{array}{l}\text { White maize dishes were more pronounced } \\
\text { on a dark background. }\end{array}$ \\
\hline \multirow[t]{3}{*}{ Scale } & Match box & $\begin{array}{l}\text { This was disregarded because smoking is a risk factor for } \\
\text { cancer and would send mixed messages. }\end{array}$ \\
\hline & Ruler & A ruler is not a known or much used item in this rural area. \\
\hline & Knife and fork & These utensils are not frequently used in the area. \\
\hline
\end{tabular}

\subsection{Evaluation of Draft 1 of the Food Photograph Series}

An expert panel (consisting of two research dieticians and a research nutritionist experienced in the development of dietary assessment methods and the culture of isiXhosa speaking people) evaluated 
Draft 1 of the FP series. A second set (Draft 2) of FPs was subsequently developed to address the comments by the expert panel.

\subsection{Evaluation of Draft 2 of the Food Photograph Series}

Draft 2 of the FP series was evaluated by means of FGD in the area. Xhosa women aged 18-55 years who were born and raised in the area were invited to participate in the FGD $(n=56)$. Men were excluded from the FGD since food preparation is regarded as "women's business" in these areas [7-9].

Two nurses from the area were trained to facilitate the FGD using a structured interview guide prepared by the research team. Two local women, who were identified by the facilitators to host the discussions, were provided with information regarding the number and age of the required participants. The women invited participants according to the inclusion criteria.

Participants critically reviewed and discussed whether Draft 2 of the FP series truly reflected the various traditional dishes and portion sizes consumed by adults in the area. All discussions were audio-recorded, transcribed and translated to English by an isiXhosa speaking interviewer. A third draft of FP series (Draft 3) was developed to address the relevant comments raised by the FGD participants.

\subsection{Evaluation of Draft 3 of the Food Photograph Series}

A final FGD was conducted with 12 women aged 18-55 years who had been raised in the area. The participants critically reviewed and discussed the applicability and recognisability of these photographs to the target population and also identified the three most recognisable and commonly consumed ratio photographs. The appropriateness of the actual sizes of the photos was also discussed.

Information obtained from the various methods described above was integrated to provide a final FP series to accompany the newly developed M-FFQ [7].

\subsection{Ethics}

Ethical approval for the study was obtained from the Research Ethics Committees of the University of Cape Town (UCT) (123/2003) and the Medical Research Council (MRC) of South Africa. Each participant received detailed, easy to understand information (both verbally and written) regarding the study, and written consent was obtained in the participant's first language (isiXhosa).

\section{Results}

\subsection{Socio-Demographic Description of Participants in the Quantitative and Qualitative Assessments}

In summary, mean age of the participants was 44 years $( \pm 16)$, most lived in traditional mud houses, used river water as primary water source and had either no, or limited schooling (Table 2). 
Table 2. Socio-demographic description of participants.

\begin{tabular}{|c|c|c|c|c|}
\hline $\begin{array}{l}\text { Socio-demographic } \\
\text { characteristic }\end{array}$ & $\begin{array}{c}24 \mathrm{~h} \\
\text { recalls } \\
n=159 \\
\end{array}$ & $\begin{array}{c}\text { Dishing up } \\
\text { session } \\
n=35 \\
\end{array}$ & $\begin{array}{c}\text { Focus group } \\
\text { discussions } \\
n=56 \\
\end{array}$ & $\begin{array}{c}\text { Final Focus group } \\
\text { discussion } \\
n=12 \\
\end{array}$ \\
\hline characteristic & $n(\%)$ & $n(\%)$ & $n(\%)$ & $n(\%)$ \\
\hline \multicolumn{5}{|l|}{ Education } \\
\hline No formal education & $69(43)$ & $6(17)$ & $14(25)$ & $1(8)$ \\
\hline Primary school (grade 1-7) & $60(38)$ & $15(43)$ & $15(27)$ & $3(25)$ \\
\hline Secondary school (grade 8-12) & $30(19)$ & $14(40)$ & $27(48)$ & $8(67)$ \\
\hline \multicolumn{5}{|l|}{ Employment } \\
\hline Unemployed & $87(55)$ & $25(71)$ & $28(50)$ & $4(33)$ \\
\hline Employed & $72(45)$ & $10(29)$ & $28(50)$ & $8(67)$ \\
\hline \multicolumn{5}{|l|}{ Monthly income } \\
\hline $\begin{array}{l}\text { R 500-R } 1000 \\
\text { (63-126 USD) }\end{array}$ & $142(89)$ & $23(66)$ & $49(87)$ & $5(42)$ \\
\hline$>\mathrm{R} 1000$ (126 USD) & $17(11)$ & $12(34)$ & $7(13)$ & $7(58)$ \\
\hline \multicolumn{5}{|c|}{ No. of people financially contributing to the household } \\
\hline 1 Person & $133(84)$ & $21(60)$ & $52(78)$ & $7(58)$ \\
\hline 2 Persons & $26(16)$ & $14(40)$ & $4(7)$ & $5(42)$ \\
\hline \multicolumn{5}{|l|}{ Type of housing } \\
\hline Traditional mud houses & $144(91)$ & $19(54)$ & $40(67)$ & $0(0)$ \\
\hline Brick houses & $15(9)$ & $16(46)$ & $16(28)$ & $3(25)$ \\
\hline Informal structures & $0(0)$ & $0(0)$ & $0(0)$ & $9(75)$ \\
\hline \multicolumn{5}{|l|}{ Water source } \\
\hline River water & $137(86)$ & $19(54)$ & $34(62)$ & $0(0)$ \\
\hline Communal tap & $22(14)$ & $16(46)$ & $15(27)$ & $8(67)$ \\
\hline Inside tap & $0(0)$ & $0(0)$ & $7(12)$ & $4(33)$ \\
\hline \multicolumn{5}{|l|}{ Fuel for cooking } \\
\hline Fire & $140(88)$ & $21(60)$ & $35(63)$ & $5(42)$ \\
\hline Electricity & $19(12)$ & $14(40)$ & $21(37)$ & $7(48)$ \\
\hline
\end{tabular}

\subsection{Portion Sizes and Ratios Determined by Various Methods}

Table 3 shows that portion sizes of maize dishes derived from the $24 \mathrm{~h}$ recalls ranged from $490 \mathrm{~g}$ (porridge) to $771 \mathrm{~g}$ (stiff pap and pumpkin). Results from the dishing up sessions are presented in Table 4. Soft porridge had the smallest portion sizes, and samp and beans the largest. Data on ratios are presented in Table 5.

Table 3. Portion sizes derived from 24-h recalls conducted in the Eastern Cape Province $(n=159)$.

\begin{tabular}{|c|c|c|c|c|c|c|c|}
\hline \multirow{2}{*}{$\begin{array}{l}\text { Dish } \\
n=159\end{array}$} & \multicolumn{3}{|c|}{ Percentiles } & \multirow[b]{2}{*}{ Minimum } & \multirow[b]{2}{*}{ Maximum } & \multirow[b]{2}{*}{ Mean } & \multirow[b]{2}{*}{ SD } \\
\hline & $\begin{array}{c}25 \% \\
\text { (Small) }\end{array}$ & $50 \%$ & $\begin{array}{c}75 \% \\
\text { (Large) }\end{array}$ & & & & \\
\hline Maize porridge (g) & 338 & 470 & 590 & 184 & 862 & 490 & 176 \\
\hline Stiff pap $*(\mathrm{~g})$ & 375 & 501 & 703 & 210 & 1290 & 555 & 234 \\
\hline
\end{tabular}


Table 3. Cont.

\begin{tabular}{lllllcll}
\hline Stiff pap and cabbage $(\mathrm{g})$ & 364 & 526 & 707 & 255 & 930 & 547 & 193 \\
Stiff pap and pumpkin $(\mathrm{g})$ & 656 & 727 & 824 & 524 & 1250 & 771 & 227 \\
Stiff pap and imifino **(g) & 448 & 588 & 770 & 330 & 985 & 600 & 204 \\
Stiff pap and spinach $(\mathrm{g})$ & 328 & 426 & 530 & 310 & 1170 & 531 & 323 \\
Stiff pap and beans $(\mathrm{g})$ & 445 & 544 & 765 & 376 & 935 & 613 & 232 \\
Samp and beans $(\mathrm{g})$ & 328 & 468 & 646 & 150 & 1290 & 536 & 261 \\
Amagewu $* * *(\mathrm{~mL})$ & 300 & 450 & 1000 & 200 & 1000 & 600 & 355 \\
\hline
\end{tabular}

$50 \%$ medium $=$ median; $\mathrm{SD}=$ standard deviation; $*$ Pap $=$ Porridge; $* *$ Imfino $=$ Wild green leafy vegetable;

*** Amagewu = Maize meal beverage.

Table 4. Portion sizes of six main maize dishes calculated during the dishing-up sessions $(n=35) *$.

\begin{tabular}{|c|c|c|c|c|c|c|c|}
\hline \multirow{2}{*}{$\begin{array}{l}\text { Dish } \\
n=60\end{array}$} & \multicolumn{3}{|c|}{ Inter quartile percentiles } & \multirow[b]{2}{*}{ Minimum } & \multirow[b]{2}{*}{ Maximum } & \multirow[b]{2}{*}{ Mean } & \multirow[b]{2}{*}{ SD } \\
\hline & $\begin{array}{c}25 \% \\
\text { (Small) }\end{array}$ & $50 \%$ & $\begin{array}{c}75 \% \\
\text { (Large) }\end{array}$ & & & & \\
\hline Porridge (g) & 358 & 557 & 630 & 146 & 760 & 497 & 174 \\
\hline Stiff pap $* *(\mathrm{~g})$ & 308 & 478 & 640 & 164 & 1204 & 505 & 232 \\
\hline Samp and beans (g) & 592 & 744 & 896 & 294 & 1396 & 743 & 217 \\
\hline Stiff pap and pumpkin (g) & 462 & 592 & 794 & 196 & 1201 & 626 & 237 \\
\hline Stiff pap and imifino $* * *(\mathrm{~g})$ & 426 & 512 & 710 & 102 & 1303 & 561 & 227 \\
\hline Soup $(g)$ & 466 & 608 & 726 & 228 & 916 & 587 & 177 \\
\hline
\end{tabular}

$50 \%$ medium $=$ Median; $\mathrm{SD}=$ standard deviation; * Female volunteers were asked to dish up a portion for herself and a portion for a man/husband ( 5 women did not have a man/husband thus dished up only one portion; ${ }^{* *}$ Pap $=$ Porridge; $* * *$ Imfino $=$ Wild green leafy vegetable.

Table 5. Ratios depicted on the photographs.

\begin{tabular}{lccc}
\hline \multirow{2}{*}{ Food type } & \multicolumn{3}{c}{ Ratios } \\
\cline { 2 - 4 } & $\begin{array}{c}\text { Cooked maize: } \\
\text { Vegetable }\end{array}$ & $\begin{array}{c}\text { Cooked maize: } \\
\text { Vegetable }\end{array}$ & $\begin{array}{c}\text { Cooked maize: } \\
\text { Vegetable }\end{array}$ \\
\hline Stiff pap + imifino & $1: 1$ & $1: 2$ & $2: 1$ \\
Stiff pap $*+$ spinach & $1: 1$ & $1: 2$ & $2: 1$ \\
Stiff pap $*+$ pumpkin & $1: 3$ & $3: 1$ & $1: 2$ \\
Stiff pap $*$ dried beans & $1: 2$ & $2: 1$ & $1: 3$ \\
Samp and beans & $2: 1$ & $3: 1$ & $5: 1$ \\
Soup & $1: 1$ & $2: 1$ & $1: 2$ \\
Mealie rice + imifino & $1: 3$ & $3: 1$ & $1: 2$ \\
Mealie rice + spinach & $1: 3$ & $3: 1$ & $1: 2$ \\
Mealie rice + pumpkin & $1: 3$ & $3: 1$ & $1: 2$ \\
\hline
\end{tabular}

* Imfino $=$ Wild green leafy vegetable; ** Pap $=$ Porridge.

\subsection{Feedback Processes Leading to Development of Final Photographs}

The initial photographs were handheld size $(10 \times 15 \mathrm{~cm})$ and were shot against a black background, on a white plate with a ruler for scale The expert group decided that the black background was too 
dark, that the ruler was not a familiar item in the area studied, and that the use of white plates made it difficult to determine portion sizes of the mostly white food items.

Draft 2 of the FP series were taken against a white background with more familiar utensils to illustrate scale (fork, knife and spoon). The food items, prepared by an isiXhosa speaking woman from the area, were dished up onto a light blue enamel plate which is commonly used in households in the area and hence familiar to the participants. Portion size photographs of the traditional beer and other maize based beverages were represented in similar blue enamel mugs. Actual size of the photographs remained the same $(10 \times 15 \mathrm{~cm})$.

During the FGD, participants commented that the hand-held photographs were too small to identify different portion sizes and that larger photographs were needed. They further commented that it was difficult to see and to determine depth of the portion sizes, especially the white maize dishes on a white background. They also mentioned that the fork, knife and spoon depicted were not acceptable as a scale for indicating dimensions and had to be replaced.

A third draft (Draft 3) of photos was taken using a black background to emphasise the mostly white foods. A light blue plate was used with a wooden spoon (most common dishing up utensil) as a scale (Figure 2). All utensils used in the photographs were procured in the EC Province. Actual size of photographs was increased to $42 \times 30 \mathrm{~cm}$ to provide life-size images of the dishes, since participants in the FGD concluded that life size photographs would be the easiest to correctly identify portion sizes.

Figure 2. (a) Draft 3, portion size photographs for stiff pap; (b) Draft 3, ratio photographs for maize meal and pumpkin.
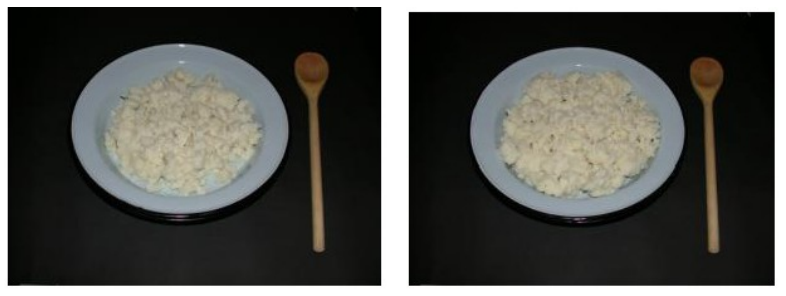

(a)
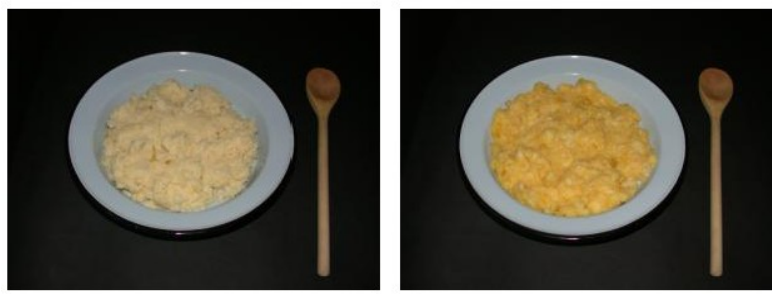

(b)
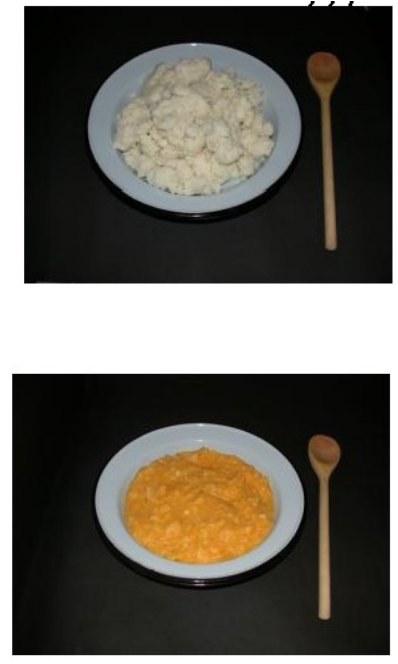

Focus group discussion participants found it difficult to estimate the three-dimensional perspective of the brown bread, cabbage, spinach and stiff pap from the photographs. This was resolved by reducing the camera angle to allow more depth [14]. Participants also did not recognise the difference between the medium and large portions of brown bread and the combined cabbage and spinach dish. These food items and dishes were repositioned on the plate and re-taken. Lastly, FGD participants indicated that the depicted portion sizes of the traditional beer were too small and suggested it be replaced with larger portion sizes, in plastic jugs. 


\subsection{Final Food Photograph Series}

The final FP series comprised three portion size photographs (S, M, L) of 21 maize food items (Figure 2a), dishes and beverages, including baked maize bread, steamed maize bread, dumplings, vetkoek, maize on the cob, whole kernels, soft porridge, stiff porridge, crumbly porridge, maize meal cooked with imifino, maize meal cooked with spinach, maize meal cooked with pumpkin, maize meal cooked with dried sugar beans, samp and dried sugar beans, soup (maize kernels and dried sugar beans), maize rice cooked with imifino, maize rice cooked with spinach, maize rice cooked with pumpkin, amagewu (maize beverage) and traditional maize beer.

The FP series also included three ratio photographs of the nine combined dishes (Figure 2b), including maize meal cooked with imifino, maize meal cooked with spinach, maize meal cooked with pumpkin, maize meal cooked with dried sugar beans, samp and dried sugar beans, soup (maize kernels and dried sugar beans), maize rice cooked with imifino, maize rice cooked with spinach, maize rice cooked with pumpkin.

Coding on the reverse side of the photographs correspond with that on the M-FFQ in order to shorten the dietary interview process and allow easy identification of the relevant portion size of a food that was consumed within the reference reporting period.

\section{Discussion}

The primary aim of the present study was to develop a FP series to improve portion size estimation when using a newly developed maize-based FFQ (M-FFQ). Both the FP and the M-FFQ were developed specifically for use in rural dwelling South Africans who are exposed to fumonisins through maize consumption [7]. A systematic approach was used to identify culturally appropriate serving sizes for the food items, dishes and beverages, and FPs were taken using these portions.

Measurement error in dietary assessment usually occurs because participants are unable to describe portion sizes accurately [10]. Predetermined portion sizes on FFQs simplify the coding and data entry process and are therefore useful in epidemiological surveys that include large numbers of participants [15]. Due to large potential between-person and within-person variation, particularly seasonally [15], the approach was to include three portion sizes for the most commonly consumed maize-based food items included in the M-FFQ. Most rural people, many of whom have low literacy levels, find it easier to identify portion sizes from local measures (cups, glasses, bundles, heaps or numbers) rather than from measuring units [16]. Two-dimensional models such as photographs and food models have been shown to increase accuracy during portion size estimation in illiterate populations [17].

A strength of the study was the use of qualitative methods, both in-depth interviews and FGD with key informants, to develop photographs as an aid to use with a quantitative dietary assessment tool [18]. Culturally-specific food preparation techniques and recipes were discussed in the FGD, and were confirmed during actual dishing-up (serving) sessions, in which the ingredients were weighed and preparation steps were recorded.

Careful consideration was given to ensure that the final food photograph series was depicted in an easy-to-identify layout with familiar utensils. In this regard, life-size photographs were found to be 
more effective than the smaller hand-held cards. This participatory research project involved support from local community representatives, recruited from the geographical area of interest. It is therefore envisioned that this culturally specific FPs will improve portion size estimation to ultimately provide more accurate information on the dietary habits and nutrient intakes of those living in rural areas in the EC Province of South Africa. However, it is of the utmost importance that the food photographs be validated to determine the presence and direction of bias in terms of portion size recalls of these participants [19]. Furthermore, the effect of only three portion size choices needs to be investigated as it is possible that more photograph choices (5-8) would decrease portion size estimation error $[19,20]$. These additional photographs should ideally represent intermediate values between the current $\mathrm{S}, \mathrm{M}$ and $\mathrm{L}$ to further obtain personalized values.

\section{Conclusions}

A FP series to improve portion size estimation of people living in rural areas of the EC Province was successfully developed using a comprehensive process of accruing qualitative and quantitative information and expert opinions, as well as very close engagement with the target community.

\section{Acknowledgements}

The study was sponsored by the South African Medical Research Council (MRC) as well as the Cancer Association of South Africa (CANSA). The authors further declare that to their knowledge there were no conflicts of interests that could bias information obtained in the paper. Ethical approval was obtained from the Research Ethics Committees of the University of Cape Town (UCT) (123/2003) and the MRC of South Africa.

\section{Conflict of Interest}

The authors declare no conflict of interest.

\section{References}

1. Somdyala, N.I.M.; Bradshaw, D.; Curtis, B.; Gelderblom, W.A. Cancer Incidence in Selected Municipalities of the Eastern Cape Province, 1998-2002. In PROMEC Cancer Registry Technical Report; MRC: Cape Town, South Africa, 2008.

2. Srivastava, M.; Kapil, U.; Chattopadhyay, T.K.; Shukla, N.K.; Sundaram, K.R.; Sekaran, G.; Nayar, D. Nutritional factors in carcinoma oesophagus: A case-control study. Asia Pac. J. Clin. Nutr. 1997, 6, 96-98.

3. Gelderblom, W.C.A.; Jaskiewicz, K.; Marasas, W.F.O.; Thiel, P.G.; Horak, R.M.; Vleggaar, R.; Kriek, N.P.J. Fumonisin-Novel mycotoxins with cancer-promoting activity produced by Fusarium moniliforme. Appl. Environ. Microbiol. 1988, 54, 1806-1811.

4. Rheeder, J.P.; Marasas, W.F.O.; Thiel, P.G.; Sydenham, E.W.; Shephard, G.S.; van Schalkwyk, D.J. Fusarium moniliforme and fumonisin in corn in relation to human esophageal cancer in Transkei. Phytopathology 1992, 82, 353-357. 
5. Marasas, W.F.O.; Jaskiewicz, K.; Venter, F.S.; van Schalkwyk, D.J. Fusarium moniliforme contamination of maize in oesophageal cancer areas in Transkei. S. Afr. Med. J. 1988, 74, $110-114$.

6. Burger, H.; Lombard, M.J.; Shephard, G.S.; Reeder, J.; van der Westhuizen, L.; Gelderblom, W.C.A. Dietary fumonisin exposure in a rural population of South Africa. Food Chem. Toxicol. 2010, 8, 2103-2108.

7. Lombard, M.J.; Steyn, N.; Burger, H.M.; Charlton, K.E.; Senekal, M.; Gelderblom, W.C.A. A proposed method to determine fumonisin exposure from maize consumption in a rural South African population using a culturally appropriate FFQ. Public Health Nutr. 2013, in press.

8. Beyers, M.J.C.; Hammer, M.L.; Groenewald, G. Foods commonly used by the Xhosa-speaking people of Transkei and Ciskei: Weights for various household measures. J. Diet. Home Econ. 1997, 7, 96-100.

9. Rose, E.F. Some observations on the diet and farming practices of the people of the Transkei. S. Afr. Med. J. 1972, 46, 1353-1358.

10. Nelson, M.; Atkinson, M.; Darbyshire, S. Food photography II: Use of food photographs for estimating portion size and the nutrient content of meals. Br. J. Nutr. 1996, 76, 31-49.

11. Labadarios, D.; Steyn, N.P.; Maunder, E.; MacIntyre, U.; Swart, R.; Gericke, G.; Huskisson, J.; Dannhauser, A.; Voster, H.H.; Nesamvuni, A.E. National Food Consumption Survey (NFCS): Children Aged 1-9 Years, South Africa. Available online: http://www.sahealthinfo.org/nutrition/ foodtitle.htm (accessed on 14 October 2007).

12. Robinson, F.; Morritz, W.; McGuiness, P.; Hackett, A.F. A study of the use of a photographic food atlas to estimate served and self-served portion sizes. J. Hum. Nutr. Diet. 1997, 10, 117-124.

13. Nel, J.H.; Steyn, N.P. Report on South African food consumption studies undertaken amongst different population groups (1983-2000): Average intakes of foods most commonly consumed. Available online: http://www.mrc.ac.zachronic/foodstudies.htm (accessed on 15 October 2009).

14. Nelson, M.; Atkinson, M.; Darbyshire, S. Food photography I: The perception of food portion size from photographs. Br. J. Nutr. 1994, 72, 649-663.

15. Hunter, D.J.; Sampson, L.; Stampfer, M.J.; Colditz, G.A.; Rosner, B.; Willett, W.C. Variability in portion sizes of commonly consumed foods among a population of women in the United States. Am. J. Epidemiol. 1988, 127, 1240-1249.

16. Kigutha, H.N. Assessment of dietary intake in rural communities in Africa: Experiences in Kenya. Am. J. Clin. Nutr. 1997, 65, 1168S-1172S.

17. Posner, B.M.; Smigelski, C.; Duggal, A.; Morgan, J.; Cobb, J.; Cupples, L.A. Validation of two-dimensional models for estimation of portion size in nutrition research. JADA 1992, 92, 738-740.

18. Satia, J.A.; Patterson, R.E.; Taylor, V.M.; Cheney, C.L.; Shiu-Thornton, S.; Chitnarong, K.; Kristal, A.R. Use of qualitative methods to study diet, acculturation, and health in Chinese-American women. JADA 2001, 100, 934-940.

19. Lucas, F.; Niravong, M.; Villeminot, S.; Kaaks, R.; Clavel-Chaplon, F. Estimation of food portion size using photographs: Validity, strengths, weaknesses and recommendations. J. Hum. Nutr. Diet. 1995, 8, 65-74. 
20. Subar, A.F.; Crafts, J.; Zimmerman, T.P.; Wilson, M.; Mittl, B.; Islam, N.G.; McNutt, S.; Potischman, N.; Faia, R.B.; Hull, S.G.; et al. Assessment of the accuracy of portion size reports using computer-based food photographs aids in the development of an automated self-administered 24-hour recall. JADA 2010, 110, 55-64.

(C) 2013 by the authors; licensee MDPI, Basel, Switzerland. This article is an open access article distributed under the terms and conditions of the Creative Commons Attribution license (http://creativecommons.org/licenses/by/3.0/). 